\title{
Культурная политика Тувинской Народной Республики по организации празднеств
}

\author{
Айлана К. Кужугет \\ Тувинский институт гуманитарных и прикладных социально-экономических исследований \\ при Правительстве Республики Тыва, Российская Федерация
}

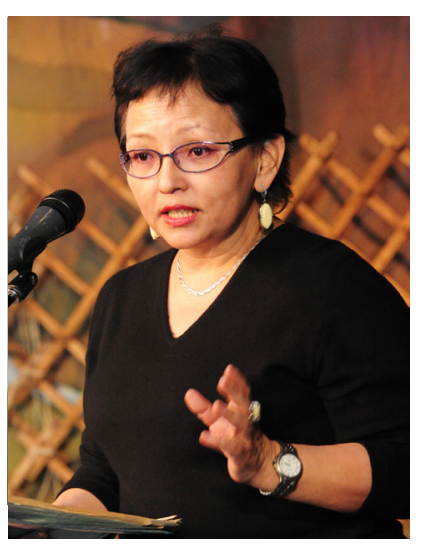

В статье анализируются особенности государственной политики Тувинской Народной Республики в 1920-1930-е годы в области организации массовых праздников в форме демонстраций и митингов, и вытеснению народных вплоть до запретов. Новые праздники были призваны показывать изменения в общественно-политической, экономической жизни народа. Анализируются факты из опубликованных трудов, а также привлекаются новые сведения из документов Национального архива Республики Тыва.

Отмечается, что культурная политика ТНР в области организации празднеств представляет собой комплекс разнородных, порой антагонистических явлений $и$ подразделяется на два периода с внутренней политикой разной направленности. В первый период - в 1920-е годы, допускались традиционные праздники, в том числе и религиозные. Во второй - с 1930-х годов - под руководством Тувинской народной революционной партии реализуется новая социокультурная политика кардинальных изменений и отказа от прошлого. Все составляющие традиционной культуры: обряды и праздники, пища и одежда, юрта, даже горловое пение и искусство резьбы по камню и дереву соотносились с понятием «отсталая культура». Праздники были не столько культурными, сколько политическими мероприятиями, поэтому их подготовкой занимались члены правительства, создавались специальные комиссии по их проведению.

За короткий исторический отрезок времени праздничная культура тувинщев подверглась значительным изменениям.

Ключевые слова: Тувинская Народная Республика; история Тувы; Тува; тувинцы; культурная политика; народный праздник; государственный праздник; социалистическая идеология

\section{Для цитирования:}

Кужугет А. К. Культурная политика Тувинской Народной Республики по организации празднеств // Новые исследования Тувы. 2020, № 3. С. 101-110. DOI: https://www.doi.org/10.25178/nit.2020.3.7

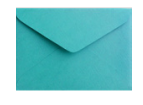

Кужугет Айлана Калиновна - доктор культурологии, кандидат искусствоведения, главный научный сотрудник Тувинский институт гуманитарных и прикладных социально-экономических исследований при Правительстве Республики Тыва. Адрес: 667000, Россия, г. Кызыл, ул. Кочетова, д. 4. Тел.: +7 (952) 752-41-00. Эл. адрес: akumin@ mail.ru

KUZHUGET, Ailana Kalinovna, Doctor of Cultural Studies, Chief Research Fellow, Tuvan Institute of Humanities and Applied Social and Economic Research under the Government of the Republic of Tuva. Postal address: 4 Kochetov St., Kyzyl, 667000, Russia. Tel.: + 7 (952) 752-41-00.E-mail: akumin@mail.ru ORCID ID: 0000-0002-6092-661X 


\title{
Cultural policy of the Tuvan People's Republic and public festivities
}

\author{
Ailana K. Kuzhuget \\ Tuvan Institute of Humanities and Applied Social and Economic Research \\ under the Government of the Republic of Tuva, Russian Federation
}

\begin{abstract}
The article discusses the main directions of the Tuvan People's Republic state policy on holiday culture in the 1920s-30s, including the introduction of new types of festivities, such as rallies or demonstrations, and suppression and ultimate prohibition of traditional rituals and holiday. The new festivities aimed to reflect the changes in the social, political and economic life of the people of Tuva. For our sources, we rely on printed materials and previously unknown documents from the National Archives of the Republic of Tuva.

As far as celebrations are concerned, the cultural policy of the PRT appeared a combination of various, often contradictory or even mutually exclusive, trends. It can be divided into two periods differing in the main orientation of the region's internal policy. In the earlier period, 1920s, traditional holidays, including religious ones, were still allowed. Later, in the 1930s, Tuvan People's Revolutionary Party pursued a new sociocultural policy which proclaimed drastic change and radical break with the past. Everything pertaining to the traditional culture: rituals and holidays, food and apparel, the yurt, even throat singing and the arts of woodcut and stone carving was labelled "backward". Festivals were political, rather than cultural, events, and thus organizing them was the government's responsibility, entrusted to ad hoc committees.

Over a short period of time, Tuvan's festival culture underwent drastic change.
\end{abstract}

Keywords: Tuvan People’s Republic; history of Tuva; Tuva; Tuvans; cultural policy; festival; public holiday; Socialist ideology

\section{For citation:}

Kuzhuget A. K. Kul'turnaia politika Tuvinskoi Narodnoi Respubliki po organizatsii prazdnestv [Cultural policy of the Tuvan People's Republic and public festivities]. New Research of Tuva, 2020, no. 3, pp. 101-110. (In Russ.). DOI: https:// www.doi.org/10.25178/nit.2020.3.7

\section{Введение}

В 1920-е и 1930-е годы в Тувинской Народной Республике (ТНР) наиболее показательными явлениями перехода от старой традиционной культуры к новой стали праздники в форме демонстраций и митингов. Они были призваны показывать изменения в общественно-политической, экономической жизни народа. Как считали лидеры коммунистического движения во главе с В. И. Лениным, маёвки, митинги, демонстрации являются лучшими формами проявления демократии угнетённых: «митингование, это и есть настоящий демократизм трудящихся, их выпрямление, их пробуждение к новой жизни, их первые шаги на том поприще, которое они сами очистили от гадов (эксплуататоров, империалистов, помещиков, капиталистов) и которое они сами хотят научиться налаживать по-своему, для себя, на началах своей, Советской, а не чужой, не барской, не буржуазной власти» (Ленин, 1969: 202; курсив источника. - A. К.). Власть в Туве, как и в Советском Союзе, уделяло большое внимание проведению государственных праздников, поскольку «массы» (как называлось население) большей частью были безграмотными или малограмотными.

Изучение государственной праздничной культуры Тувы 1920-1930-х годов на основе архивных документов, прежде всего - Национального архива Республики Тыва (далее - НА РТ), позволяет получить достоверные сведения о конкретном периоде в истории страны, понять важные составляющие внутренней политики и духовной культуры Тувы прошлого и в целом основные тенденции ее развития.

Если о бытовании народных праздников тувинцев и порядке их проведения опубликовано уже много научных работ, в том числе автора данной статьи (Курбатский, 1973; Кенин-Лопсан, 1987, 2004, 2006; Вайнштейн, 1961, 1972; Дьяконова, 1971, 1976; Потапов, 1969; Кужугет, 2006), то тема государственных праздников периода ТНР практически не изучена, что обусловливает актуальность выбранной темы. В статье рассмотрены особенности процесса становления, развития новых праздников ТНР и вытеснения народных тувинских. Данный период составляет небольшой отрезок времени - двадцать три года, тем не менее для детального восстановления всех событий применяется историко-хронологический 
метод. Кроме этого, принцип социокультурного подхода дает возможность представить события тех лет в тесной взаимосвязи с другими явлениями становления тувинского общества, ставшего на путь построения социалистического строя.

Теоретической базой изучения политики государства в области культурного строительства, в частности, празднеств явились работы исследователей советского периода (Климов, 1964; Конович, 1990; Кузьмина, Маслов, 1975; Ширяева, 1975). Широкий круг вопросов относительно роли культуры в развитии современного общества раскрывается в трудах сибирских, в частности, тувинских исследователей (Юша, 2005; Цыренова, 2007; Майны, 2014; Бадыргы, Мунге, 2020).

Источниковой базой исследования стали опубликованные труды по тувинским традиционным праздникам, а также документы Национального архива РТ (партийного фонда 7, фондов рукописей 92-1 и 93-1), ряд сведений из которых в научный оборот вводится впервые.

\section{Традиционные праздники тувинщев}

Традиционные праздники тувинцев, как мы уже отметили, довольно подробно описаны в работах тувиноведов, поэтому, опираясь на собранные материалы, мы перечислим их, чтобы представить общую картину дореволюционной обрядовой культуры.

Календарные обряды и праздники составляли самую большую группу народных торжеств. К ним относятся обряды освящения объектов природы с жертвоприношением духам, хозяевам местности с общим названием дагыыры (освящение): оваа дагыыры, даг дагыыры, арт дагыыры, Дээр дагыыры, Оран танды дагыыры, суг бажы дагыыры, хөл дагыыры, буга бажы дагыыры, аржаан дагыыры, хам ыяш дагыыры, тел ыяш дагыыры, Тайга дагыыры. Освящали: жертвенник, родовую гору, перевал, Небо, Вселенную, исток реки, озеро, начало оросительного канала, источник минеральной воды, шаман-дерево, деревоблизнец, тайгу. Большинство из обрядов и праздников проводилось ежегодно, приблизительно в одно и тоже время - весной или летом. Однако есть среди них и обряды, которые проводились и по мере надобности: при достижении перевала (apm дагыыры), для лечения больного (хам ыяш или тел ыяш дагыыры) (Яковлев, 1900; Кенин-Лопсан, 2006; Курбатский, 1973; Кужугет, 2006).

Семейными праздниками являются от дагыыры - освящение домашнего очага, куда - свадьба, уруг дою - праздник обрезания волос в трехлетнем возрасте, ойтулааш - молодежный праздник, на котором молодые люди из разных родов знакомились со своими будущими супругами (Кенин-Лопсан, 2004; Кужугет, 2006).

К религиозным обрядам и праздникам относятся шаманские камлания и буддийское богослужение Цам (тув. - Сам) (Дьяконова, 1971; Кенин-Лопсан, 1987; Кужугет, 2006).

Отдельно надо отметить самый большой праздник встречи Нового года - Шагаа (у монголов Цагаан сар - Белый месяц), в прошлом, вероятно, называвшийся Чыл бажы (начало года), как у соседних тюркских народов.

Мы разделяем традиционные праздники на календарные, семейные и религиозные, но, понятно, что в повседневной жизни были тесно взаимосвязаны и могли быть как семейными, так и религиозными. Эта созданная в течение многих веков система обрядов и праздников охватывала все стороны жизни тувинцев и полностью удовлетворяла их психологическим, эмоциональным, эстетическим вкусам и потребностям (Курбатский, 1973; Кенин-Лопсан, 2006).

\section{Начало формирования новых празднеств}

В первое десятилетие ТНР ещё сохранялись частично некоторые обряды и праздники, но место ведущих начали занимать празднества, организованные государством, а не народом, поэтому они уже назывались не народными, а государственными. Поскольку Тува встала на путь строительства социализма, праздники копировались у Советского Союза. Это были не только праздники 1 Мая, 7 ноября, но и различные празднования юбилеев и памятных дат жизни великих писателей, к примеру, в 1937 г. - 100-летие со дня смерти А. С. Пушкина, олимпиады и смотры художественной самодеятельности. Однако, главными среди этих крупных культурных событий являлись все же политизированные празднества в форме парадов и демонстраций.

Как известно, первый состав правительства ТНР (1921-1929) состоял из бывших нойонов и представителей буддийского духовенства, поэтому принципы и порядок построения структуры государственной власти в Туве историки характеризуют «как переходные с элементами демократии, вы- 
соким общественным статусом института церкви и первыми отчетливыми признаками будущего партократического устройства» (История Тувы, 2007: 136).

В протоколе заседания Центрального комитета Танну-Тувинской Народной Партии (ЦК ТНРП) от 6 дня 11 луны 3 года (приблизительно 16 декабря 1923 г.), на котором присутствовали Дондук - заместитель председателя ЦК, Лодан-Шыырап - член ЦК, Буян-Бадорху - премьер-министр, Данзын в. и. о. министра внутренних дел, Павел Медведев - советник, в пункте 2 «Об установлении праздничных дней» записано:

«Для чествования образования самостоятельной республики Танну-Тува установить следующие праздничные дни:

1. День создания угудар ямы (оргбюро) и объединения Танну-Тува -8 дня 10 луны 1 года (1921 г.);

2. День образования Танну-Тувинского правительства и создания Танну-Тувинской народной республики - 13 дня 12 луны 1 года (28 февраля - 1 марта 1922 г.);

3. День установления партии и распространение партийного влияния в стране -25 дня 5 луны 3 года (6 июня 1923 г.);

4. Оставить празднование нового года (Шагаа) как традиционный старинный праздник.

Кроме того, чествовать с празднованием 7 ноября - праздник Великой Октябрьской социалистической революции, давшей свободу и мирную жизнь трудящимся всех наций мира» (НА РТ, фп. 1, оп. 1, д. 69, л. 31-32).

В одном из первых материалов - в протоколе заседаний ЦК ТНРП №1-22, от 6 дня 11 луны 3 года (16 декабря 1923 года) первого состава заседания ЦК ТНРП был выработан список государственных праздников: образование государства, правительства, партии, Шагаа. Причём, в том же документе записано, что в ознаменование двух праздников - установления партии и Шагаа произвести амнистию осужденных. «Обсудив вопрос, об облегчении меры наказания и амнистии осужденным, решили, что в праздничные дни в день установления партии - 25 дня 5 луны и новогодний праздник (Шагаа) считает возможным произвести амнистию и облегчение срока наказания из числа осужденных по разным преступлениям, если это считается возможным (НА РТ, фп. 1, оп. 1, д. 69, л. 32)». Это говорит о том, что государство хотело подчеркнуть важность праздников и донести это до общества.

На заседании 5 апреля 1924 г. было принято также решение о разрешении совершения буддийских богослужений. При этом «сбор средств для проведения и нужд молитвенной службы в монастырях (хурэ) считать только добровольным делом верующих граждан» (НА РТ, фп. 1, оп. 1, д. 124, л. 9). 13 ноября 1924 г. на совместном заседании членов ЦК ТНРП с представителями от хурээ республики обсуждались вопросы об оказании помощи монастырям и бедным ламам, о дополнительном наборе хуураков (учеников лам), о распространении религиозной пропаганды и освоении религиозных знаний (НА РТ, фп. 1, оп. 1, д. 124, л. 65-68).

В начале 1920-х годов ещё проводились календарные праздники, религиозные богослужения, шаманские камлания, а со второй половины 1920-х гг. и установленные государственные праздники. В Протоколах ЦК ТНРП в 1925 г. уже важное значение отводилось празднованию 1 Мая: «провести праздник 1-го мая повсеместно (НА РТ, фп. 1, оп. 1, д. 158, л. 16)». Также в Протоколе № 11 от 22 дня 5 луны 5 года (13 июля 1925 г.), в разделе «Дополнительные вопросы», рассматривалась необходимость празднования дня образования Танну-Тувинской Народно-Революционной Партии: «тувинский народ, сбросив старый строй и эксплуататоров, получил самостоятельность и свободу, страна развивается по новому пути. Поэтому ранее установленный праздник - день образования Танну-Тувинской народнореволюционной партии провести 25-30 дня 5 луны с. г. (НА РТ, фп. 1, оп. 1, д. 158, л. 39).

С 1929 г. политика партии начала меняться: это подтверждается документами. Так, в Резолюции VIII съезда ТНРП (10 ноября 1929 г.) по докладу о задачах культурного строительства в ТНР отмечалось, что:

«...современное состояние культурного уровня населения Тувинской республики очень низко. Родной письменности не имеется, своя национальная культура не развита. Грамотность населения на монгольском языке равна 1,5 \%. Грамотных женщин почти нет. Грамотного мужского населения значительную долю составляют феодальные слои населения и ламство. Культурные кадры работников исчисляются единицами... Религия имеет большое влияние. Количество хурэ в республике равно 22 и количество лам приблизительно 2000 (НА РТ, фп. 1, оп. 1, д. 583, л. 28)»;

«...Ламство являясь категорией паразитической, эксплуататорской, околпачивающей темные аратские массы, по природе своей реакционно, и наши новые начинания в области культурного строительства, 
несомненно, встретят соответствующий отпор со стороны лам и прочих реакционных элементов, которые до сих пор имеют значительное влияние на население. Задача партийной организации сейчас состоит в том, чтобы вести более усиленную борьбу с ламством и всякими религиями и в соответствии с этим развернуть широкую агитационно-разъяснительную работу в аратских массах. Для того, чтобы успешно проводить эту работу, необходимо максимально усилить антирелигиозное воспитание членов НРП и РСМ и решительно искоренять явления, связанные с выполнением религиозных обрядов и других предрассудков членами НРП (НА РТ, фп. 1, оп. 1, д. 583, л. 32)»;

«...Наряду с этим необходимо в партийно-просветительской работе обратить серьезное внимание на борьбу с националистическими, с монголофильскими и панмонголистскими, с родовыми и местническими настроениями и взглядами (НА РТ, фп. 1, оп. 1, д. 583, л. 34)».

Таким образом, в 1929 г. врагами тувинского общества объявлялись «ламство и всякие религии». Однако немецкий путешественник О. Менхен-Хелфен, побывавший в Туве именно в 1929 г., стал очевидцем одного из последних буддийских праздников перед окончательным запретом на их проведение:

«почти тысяча тувинцев со всего Хемчика: мужчины и женщины в праздничных одеждах, украшенных вышивкой шелковых нарядах, которые, кстати, как и хороший нюхательный табак, постепенно исчезают, собрались на праздник. Подобно тому, как это бывает во время католического праздника Тела Христова, процессия обошла все четыре алтаря вокруг монастыря. У алтарей шествие приостанавливалось, большие фигуры богов опускали на землю, а те, кто нес роскошные храмовые знамена, выстраивались рядом с ними» (Менхен-Хелфен, 2007: 294).

Рассказ очевидца свидетельствует о том, что народ продолжал следовать традиционным религиозным празднествам - вплоть до запрета.

Итак, 1920-е годы были особым десятилетием в истории ТНР, когда государство проводило осторожную политику на введение новых государственных праздников, тем не менее не запрещая, и даже поощряя и традиционные праздники.

\section{Становление системы государственных празднеств}

Новая политика ТНР в области культуры началась в 1930-м году, с началом деятельности С. К. Токи. Конституция Тувы 1930 г. ввела положение о диктатуре трудящихся аратов и новое название государства «Тувинская Аратская Республика (ТАР)». Ее 2-я статья гласила: «Настоящая Конституция (основной закон) Тувинской Аратской Республики имеет своей целью гарантировать диктатуру трудящихся аратских масс в целях подавления баев, феодалов, теократов и уничтожения всякой эксплуатации человека человеком» (Конституции Тувы, 1999: 49-50). Также, согласно этой конституции запрещалось «проводить религиозные мероприятия без специального письменного разрешения местных органов..., а также проведение традиционных обрядов, связанных с культом природы, в которых обычно принимали участие ламы и шаманы и празднование традиционного Нового года по лунному календарю - Шагаа» (История Тувы, 2007: 261-262).

Свидетели событий начала 1930-х годов рассказывали, что некоторые председатели первых колхозов разрешали проводить обряды, к примеру, после проведения посевов зерновых, как было принято раньше, однако получали за это строгие взыскания по партийной линии. Больше всех пострадал молодежный праздник ойтулааш. Участник кампании по его запрещению М. С. Бегзи вспоминал:

«...мы свято выполняли указания Центрального Комитета ТНРП и древняя тувинская народная игра ойтулааш стала вредной, отсталой и заразной для строительства новой жизни в Туве (цит. по: Кенин-Лопсан, 2004: 35)».

Закончил свой рассказ М. Бегзи фразой:

«Мы, активисты сумона, ездили по сумону и ловили молодежь. Затем собирали всех участников игры и их родителей, чьи имена заносили в список. В центре сумона Ак-Туруг мы строго допрашили каждого, а активистов передавали в суд сумона. Насилие дало свой результат: тихо стало в Чаа-Холе, перестали звучать ночные песни влюблённых. Однако тревога продолжала жить в людях» (там же: 38).

Решительность второго состава правительства ТНР по отношению к религиозным деятелям и обрядам, ими совершаемым, достаточно четко выразилась уже в 1930 г. Так в «Резолюции коллегии Восточного секретариата ИККИ по тувинскому вопросу от 25 марта 1930 по докладу Райтера», отмечалось что:

«...отличительной чертой последнего периода развития Тувы является неправильная политика старого руководства партии, отражавшая интересы феодальных и эксплуататорских элементов страны, в ос- 
новном сводившиеся к торможению социального перестройства и поставившее под угрозу дальнейший некапиталистический путь развития ТНР (с 1921-1930) (НА РТ, фп. 1, оп. 1, д. 856, л. 1)»;

«...Значительным тормозом в революционном преобразовании страны является ламство, продолжающее играть большую роль в хозяйственной и политической жизни (НА РТ, фп. 1, оп. 1, д. 856, л. 3)»;

«...Если в текущий период партия провела ряд политических и хозяйственно-культурных мероприятий по ослаблению влияния ламства на аратские массы, то подобные мероприятия в отношении шаманства отсутствуют. Шаманство пользуется в аратских массах значительно большим влиянием и в последнее время (в связи с уменьшением роли ламства) относительно укрепило свое положение. Отсюда следует, что необходимо развернуть широкую культурно-просветительскую (а среди членов партии антирелигиозную) пропаганду, направляя ее не только против ламства, но также против шаманства (НА РТ, фп. 1, оп. 1, д. 856, л. 10)».

С 1930-го года все устремления нового правительства теперь были обращены исключительно к СССР, культура которого стала и для тувинцев образцом для подражания. В документе, который хранится в НА РТ, под названием «Доклады о культурном строительстве и материалы по партпросвещению, школам и другим отраслям. 1933-1934 гг.», написано: «Можно привести ряд примеров, показывающих, насколько далеко в отдельных случаях шагнул вперед быт арата по пути культурности. Например, квартира тов. Тамдыкжапа - председателя Улуг-Хемского хошуна состоит из двух комнат (или точнее из кухни и комнаты). У него и жены стоят европейские кровати с чистыми накидками, на стене - географическая карта; вдоль стен - столы, на одном лежит литература, в комнате чисто, достаточно табуреток; тов. Тамдынжап пользуется для чая самоваром (НА РТ, фп. 1, оп. 1, д. 1034, л. 22)».

Однако ревсомольцы не только боролись со старыми традициями, но и устанавливали новые. В частности, своими силами проводили торжества. П. П. Маслов, руководивший переписью населения в ТНР в 1930-1931 гг., описал революционный юбилей - десятилетие тувинской национальной армии:

«по случаю же десятилетия народно-революционной армии в городе были шумные торжества. Но там не было никаких спектаклей, в хошунных же центрах составлялись труппы из ревсомольцев. Представлены были пьесы, которых, разумеется, никто не писал; всё целиком требовалось импровизировать... Представление кончилось. Молодой ревсомолец произносит горячую речь о революционных событиях истекших лет. Он призывает к укреплению завоеваний и к дальнейшей борьбе за социализм» (Маслов, 2007: 670).

Так директивно, достаточно жёстко правительство С. К. Токи пыталось в сжатые сроки изменить тувинское общество. Задачи ввести новые праздники, изменить образ жизни, внешний облик тувинцев периода ТНР были выполнены.

В 1930-е гг. новые празднества должны были быстро и безвозвратно изменить сознание населения THР. Огромное значение правительством уделялось наглядной агитации - символам нового социалистического строя: флагам на всех государственных зданиях, украшениям трибун, лозунгам, а также тщательной подготовке торжественных собраний во всех коллективах и учебных заведениях и театрализованных инсценировок. Так в документе заседания Правительства ТНР в 1930 г. о «роведении годовщины Октябрьской революции» записано:

«...накануне годовщины Октябрьской революции на всех правительственных, кооперативных, а также частных учреждениях вывешиваются флаги. Арку Миннархоза и Здания правительства и Партии украшают месткомы Миннархоза и Рабпроса. Украшение ворот и зданий Т.Ц.К. и Тувинбанка поручается коллективам Т.Ц.К. и Тувинбанка... Трибуну поручается украсить коллективу горного отдела и загранместкома... Лозунги для вышеупомянутых Арок, зданий, трибуны и Братской могилы поручается написать вышеупомянутым коллективам... Поручить комсомолу и ревсомолу провести карнавал после торжественного собрания на тему «за новый быт, за культурную революцию и на тему антирелигиозную организовать летучие инсценировки» (НА РТ, фп. 1, оп. 1, д. 962, л. 1-2).

В архивном документе 1933 г. под названием «Материалы по проведению праздников, доклады о 1 мая, 9 годовщины смерти В. И. Ленина за 1933 г.» записано распоряжение по всем хошунам:

«30 апреля проводятся торжественные заседания с докладом о значении праздника 1 мая. 1 мая утром устраивают демонстрацию и проводят митинги, после которых организуются спортивные выступления и игры. Вечером устраиваются бесплатные постановки и художественные вечера» (НА РТ, фп. 1, оп. 1, д. 1602, л. 28);

«...готовятся пьесы “Не разойдемся”, “Новый путь” на тувинском языке. 30 апреля будет проведен детский утренник. Оборудуется в городе спортплощадка. Будут показаны фигурные размещения “1 мая”, бег, борьба. 2 мая - велогонки и бег с препятствиями, и другие военизированные упражнения» (HA PT, фп. 1, оп. 1, д. 1602, л. 57). 
Лозунги, подготовленные к 1 мая 1933 г., отражают все политические задачи партии и правительства. Это своеобразная политинформация, озвученная в праздник из радиодинамиков:

«Да здравствует 1 мая - день боевого строя революционных сил международного пролетариата! Да здравствует единый фронт трудящихся и угнетённых всего мира против мирового империализма! Долой японских интервентов, порабощающих Китай и грозящих независимости Монгольской Народной республики и Тувы! Да здравствуют Китайские Советы, борющиеся за освобождение многомиллионных трудящихся масс Китая из-под ига иностранных захватчиков и отечественных феодалов, и капиталистов! Долой фашистских убийц и провокаторов! Да здравствует революционный пролетариат Германии! Братский привет трудящимся СССР, успешно закончившим под руководством ВКП(б) во главе с тов. Сталиным первую пятилетку и строящим бесклассовое социалистическое общество! Беспощадный огонь по проявлениям великорусского шовинизма и местного национализма. Да здравствует дружественная взаимопомощь аратов и граждан СССР, живущих в Туве, в разрешении задач строительства независимой Тувинской Народной Республики» (НА РТ, фп. 1, оп. 1, д. 1602, л. 25-26).

По образцу проведения праздников 1 Мая и 7 ноября, заимствованных у братского Советского Союза, стали проводиться и празднества местного значения. Согласно плану проведения праздника, посвященного XXII годовщине ТНP, 13 августа проводился:

«Общий парад и митинг, Построение бюста Сталина, Построение цифры XXII, Инсценировка “ТНР в дни войны".

1. Гимнастические упражнения женской группы - трудовые движения

2. Пляска детской группы

3. “Тревога” - исполнение духового оркестра, световые эффекты

4. «Рота в наступлении» - перебежки, переползания

5. Упражнения с винтовками

6. Упражнения с клинками

7. Живой танк

8. “Фанфары играют отбой”: танк рассыпается на построение пятиконечной звезды

9. Мирный отдых - веселье: упражнения детской группы, танец артистов Гостеатра, хор ансамбля ЦК Профсовета, упражнения с медецинбаллами, Танец балетной группы Гостеатра, Жонглеры Гостеатра, акробаты Гостеатра, пирамидка из упражнения Гостеатра.

Заключительная пирамида - пятиконечная трехярусная звезда с аншлагом “Победа Советского народа есть также победа тувинского народа” Красный обоз подарков от ТНР - Красной Армии.

Преодоление препятствий на лошадях. Национальная борьба - одновременно 32 пары, борьба 16 пар, рубка лозы на лошадях, борьба 8 пар, джигитовка; (1) борьба 4 пар; трудовая эстафета - построение юрты; борьба 2 пар, перетягивание каната; финал борьбы» (НА РТ, фр. 93, оп. 1, д. 449, л. 2).

Таким образом, государственные праздники утверждали в сознании людей новые ценности и идеалы, пропагандировали политические идеи.

Слово «революция» чуть позднее стало использоваться в словосочетании «культурная революция» (термин впервые введён В. И. Лениным в 1923 г. в работе «О кооперации»). Её задачей было формирование общества с новой социалистической культурой, это касалось и образования (кружки по ликвидации безграмотности, так называемые ликбезы), а также создание новых, ранее неизвестных тувинскому народу видов искусства: литературы, театра, хореографии, изобразительного искусства: живописи, графики, в том числе книжной и плакатной. И среди всех этих новых явлений, безусловно, государственные праздники играли наиважнейшую роль. Они были массовыми, достаточно однообразными, часто участие в них было принудительным. По сути, это были праздники, состоявшие из митингов, демонстраций, военных парадов, спортивных показательных упражнений, концертных номеров, лозунгов, призывавших к строительству социализма.

В Национальном архиве РТ хранятся материалы по организации празднеств, к примеру: «Планы проведения празднования X-XIII годовщины ТНР и других праздников». Так, к 10-летию ТАР записано:

«Смотр достижений тувинской письменности, премирование и заключение новых соцдоговоров на быстрейшее распространение письменности в худоне. Широкое распространение изданий ТУвГИЗа и проведение кампаний по вербовке новых подписчиков “Шын”. Усиление пропаганды санитарии и гигиены и борьба за новый и здоровый быт арата...

Накануне праздника, т. е. 6-го июля провести в хошунах торжественные собрания с докладом и приветствиями ТАР по прилагаемым тезисам и приветствиям. 
7-го июля провести митинги и демонстрации. После демонстрации организовать массовые праздничные выступления (игры, состязания, инсценировки и пр.). Подвести после окончания празднования политические итоги и материалы направить в центральную комиссию.

Основные задачи и лозунги празднования. 1.Укрепление связи с СССР - оплотом мировой революции и социалистического строительства в Туве. 2. Решительное выкорчёвывание остатков феодальных отношений в стране, развертывание социалистического строительства (НА РТ, фр. 93, оп. 1, д. 31, л. 3, 3 об.,4)».

В 1930-е годы процесс формирования новых социалистических празднеств приобрёл более логический целенаправленный характер по сравнению с 1920-ми годами. Праздники готовились по заранее утвержденному Центральным комитетом партии и правительством сценариям, которые подразделялись на торжественную часть и культурный досуг. Заранее намечались ответственные организации за украшение зданий, подготовку транспарантов с лозунгами, предварительно обсужденными и предложенными комиссией.

\section{Заключение}

Празднествам в период ТНР уделялось большое внимание. При их проведении, по мнению партийных деятелей, у народа формировались новые установки.

Культурная политика ТНР в области организации празднеств представляет собой комплекс разнородных, порой антагонистических явлений и подразделяется на два периода с внутренней политикой разной направленности. Если в первый - 1920-е годы, допускались традиционные праздники, в том числе и религиозные, то, начиная с 1930-х годов - это уже социокультурная политика кардинального изменения тувинского общества, имеющая характер довольно жёсткой его трансформации.

С. К. Тока, поставивший для себя задачу привести Туву в состав СССР, считал, что надо любыми средствами подготовить к этому население республики. В своих выступлениях он повторял ключевую фразу: «С прошлым покончено навсегда!» (Тока, 1987: 41), исключая не только тяжелое прошлое маньчжурского ига, но и всю традиционную культуру тувинцев. Начиная с 1930-х гг. все составляющие традиционной культуры: обряды и праздники, пища и одежда, юрта, даже горловое пение и искусство резьбы по камню и дереву соотносились с понятием «отсталая культура».

Праздники были не столько культурными, сколько политическими мероприятиями, поэтому их подготовкой занимались члены правительства, создавались специальные комиссии по их проведению.

За короткий исторический отрезок времени Тувинская народная революционная партия практически изменила праздничную культуру тувинцев, отменив в 1930-е годы народные обряды и праздники, введя новые торжества с социалистическими символами, торжественными собраниями, лозунгами, демонстрациями, культурной программой, спортивными соревнованиями. В дальнейшем мы планируем исследовать эту тему в отдельном издании.

\section{СПИСОК ЛИТЕРАТУРЫ}

Бадыргы, М. М., Мунге, Б. В. (2020) Документы Национального архива Республики Тыва по культурному строительству Тувинской Народной Республики // Новые исследования Тувы. № 2. C. 145-164. DOI: www.doi. org/10.25178/nit.2020.2.10

Вайнштейн, С. И. (1961) Тувинцы-тоджинцы. Историко-этнографические очерки. М. : Издательство восточной литературы. 216 с.

Вайнштейн, С. И. (1972) Историческая этнография тувинцев. М. : Наука. 312 с.

Дьяконова, В. П. (1971) Цам у тувинцев // Религиозные представления и обряды народов Сибири в XIX - начале ХХ в. / отв. ред. С. В. Иванов. Л. : Наука. 301 с. С. 113-128.

Дьяконова, В. П. (1976) Религиозные представления алтайцев и тувинцев о природе и человеке // Природа и человек в религиозных представлениях народов Сибири и Севера / отв. ред. И. С. Вдовин. Л. : Наука. 336 с. С. $268-292$.

История Тувы (2007) / отв. ред. В. А. Ламин. Новосибирск : Наука. Т. II. 430 с.

Кенин-Лопсан, М. Б. (1987) Обрядовая практика и фольклор тувинского шаманства. Конец XIX - начало XX века. Новосибирск : Наука.164 с.

Кенин-Лопсан, М. Б. (2004) Ойтулааш. Классические образцы любовной лирики тувинского народа. Кызыл : Новости Тувы. 383 с. 
Кенин-Лопсан, М. Б. (2006) Традиционная культура тувинцев. Кызыл : Тувинское книжное издательство им. Ю. Ш. Кюнзегеша. 232 с.

Климов, Е. Н. (1964) Новые обычаи и праздники. М. : Профиздат. 172 с.

Конович, А. А. (1990) Театрализованные праздники и обряды в СССР. М. : Высшая школа. 208 с.

Конституции Тувы. 1921-1993 гг. (1999) / отв. ред. К. А. Бичелдей. Кызыл : Тувинское книжное издательство. 315 c.

Кужугет, А. К. (2006) Духовная культура тувинцев: структура и трансформация. Кемерово: КемГУКИ. 320 с.

Кузьмина, Т., Маслов Е. (1975) Праздникам и обычаям - новое социалистическое содержание. М. : Профиздат. 268 c.

Курбатский, Г. Н. (1973) Тувинские праздники. Кызыл: Тувинское книжное издательство. 90 с.

Ленин, В. И. (1969) Полное собрание сочинений: в 55-ти т. 5-е изд. М.: Издательство политической литературы. T. 36. 741 c.

Майны, Ш. Б. (2014) Народные игры в традиционной культуре тувинцев: историко-культурологический анализ: автореф. дис. ... канд. культ. Кемерово. 23 с.

Маслов, П. П. (2007) Конец Урянхая. Путевые очерки // Урянхай. Тыва дептер: в 7 т. / сост. С. К. Шойгу. М.: Слово. T. 5. Урянхайский край: от Урянхая к Танну-Туве (конец XIX - первая половина XX в.). 735 с. С. 618-729.

Менхен-Хелфен, О. (2007) Путешествие в азиатскую Туву // Урянхай. Тыва дептер: в 7 т. / сост. С. К. Шойгу. М. : Слово. Т. 6. Танну-Тувинская Народная Республика (1921-1944 гг.) 583 с. С. 220-351.

Моллеров, Н. М. (2005) История советско-тувинских отношений (1917-1944 гг.). М. : Издательство Московского гуманитарного университета. 325 с.

Потапов, Л. П. (1969) Очерки народного быта тувинцев. М.: Наука. 402 с.

Тока, С. К. (1987) Навеки вместе // Слава Октябрю! / отв. ред А. К. Канзай. Кызыл: Тувинское книжное издательство. 219 с. С. $15-49$.

Ширяева, П. Г. (1975) Из истории развития некоторых революционных традиций // Советская этнография. № 6. C. 63-70.

Цыренова, 3. Е. (2007) Традиционная культура коренных народов Восточной Сибири (1920 - конец 1980-х гг.): опыт сохранения развития: автореф. дис. ... д-ра истор. наук. Улан-Удэ. 51 с.

Юша, Ж. М. (2005) Традиционная народная обрядовая поэзия тувинцев: структура и семантика : дисс. ... к. ф. н. Новосибирск. 194 с.

Яковлев, Е. К. (1900) Этнографический обзор инородческого населения долины Южного Енисея и объяснительный каталог этнографического музея. Минусинск : Типография В. И. Корнакова. 220 с.

Дата поступления: 15.06.2020 г.

\section{REFERENCES}

Badyrgy, M. M. and Munge, B. V. (2020) Dokumenty Natsional'nogo arkhiva Respubliki Tyva po kul'turnomu stroitel'stvu Tuvinskoi Narodnoi Respubliki [“Cultural Upbuilding” in People’s Republic of Tuva in documents preserved at National Archives of Republic of Tuva]. New Research of Tuva, no. 2, pp. 145-164. (In Russ.). DOI: www.doi.org/10.25178/ nit.2020.2.10

Vainshtein, S. I. (1961) Tuvintsy-todzhintsy. Istoriko-etnograficheskie ocherki [Tozhu Tuvans: historical and ethnographic essays]. Moscow, Nauka. 218 p. (In Russ.).

Vainshtein, S. I. (1972) Istoricheskaia etnografia tuvintsev. Problemy kochevogo khoziaistva [Historical Ethnography of Tuvans. Problems of nomadic economy]. Moscow, Nauka. 314 p. (In Russ.).

D'iakonova, V. P. (1971) Tsam u tuvintsev [Tsam among Tuvans]. In: Religioznye predstavleniia $i$ obriady narodov Sibiri v XIX - nachale XX v. [Religious representations and rites of the peoples of Siberia in the XIX-early XX century] / ed. by S. V. Ivanov. Leningrad, Nauka. 301 p. Pp. 113-128. (In Russ.).

D'iakonova, V. P. (1976) Religioznye predstavleniia altaitsev i tuvintsev o prirode i cheloveke [Religious beliefs of Altaians and Tuvans about nature and man]. In: Priroda i chelovek v religioznykh predstavleniiakh narodov Sibiri i Severa [Nature and man in the religious beliefs of the peoples of Siberia and the North] / ed. by I. S. Vdovin. Leningrad, Nauka. 336 p. Pp. 268-292. (In Russ.).

Istoriia Tuvy [The History Of Tuva] (2007): in 3 vols. / ed. by V. A. Lamin. Novosibirsk, Nauka. Vol. 2. 430 p. (In Russ.). 
Kenin-Lopsan, M. B. (1987) Obriadovaia praktika i fol'klor tuvinskogo shamanstva. Konets XIX - nachalo XX v. [Ritual practice and folklore of Tuvinian shamanism. Late XIX - early XX century]. Novosibirsk, Nauka. 165 p. (In Russ.).

Kenin-Lopsan, M. B. (2004) Oitulaash. Klassicheskie obraztsy liubovnoi liriki tuvinskogo naroda [Oitulaash. Classic examples of love lyrics of the Tuvan people]. Kyzyl, Novosti Tuvy. 383 p. (In Russ.).

Kenin-Lopsan, M. B. (2006) Traditsionnaia kul'tura tuvintsev [Traditional culture of Tuvans]. Kyzyl, Tuvan book publisher. 232 p. (In Russ.).

Klimov, E. N. (1964) Novye obychai i prazdniki [New customs and holidays]. Moscow, Profizdat. 172 p. (In Russ.).

Konovich, A. A. (1990) Teatralizovannye prazdniki i obriady $v$ SSSR [Theatrical holidays and ceremonies in the USSR]. Moscow, Vysshaia shkola. 208 p. (In Russ.).

Konstitutsii Tuvy [Constitutions of Tuva] (1999): a collection for the 55th anniversary of Tuva's accession to the USSR and RSFSR. Kyzyl, Tuvan book publishing house. 216 p. (In Russ.).

Kuzhuget, A. K. (2006) Dukhovnaia kul'tura tuvintsev. Struktura i transformatsiia [The immaterial culture of Tuvans. Structure and transformation]. Kemerovo, KemGUKI. 319 p. (In Russ.)

Kuz'mina, T. and Maslov E. (1975) Prazdnikam i obychaiam - novoe sotsialisticheskoe soderzhanie [Holidays and customs a new socialist content]. Moscow, Profizdat. 268 p. (In Russ.).

Kurbatskii, G. N. (1973) Tuvinskie prazdniki [Tuvan holidays]. Kyzyl, Tuvat book publishing house. 90 p. (In Russ.).

Lenin, V. I. (1969) Polnoe sobranie sochinenii [Complete works]: in 55 vols. 5nd ed. Moscow, Izdatel'stvo politicheskoi literatury. Vol. 36. 741 p. (In Russ.).

Mainy, Sh. B. (2014) Narodnye igry v traditsionnoi kul'ture tuvintsev: istoriko-kul'turologicheskii analiz [Folk games in the traditional culture of Tuvans: historical and cultural analysis]: Abstract of Diss.... Candidate of Cultural Studies. Kemerovo. 23 p. (In Russ.).

Maslov, P. P. (2007) Konets Uriankhaia. Putevye ocherki [The End Of Urianhai. Travel essays]. In: Uriankhai. Tyva depter [Uriankhai: A Tuvan Notebook]: in 7 vols. / comp. by S. K. Shoigu. Moscow, Slovo. Vol. 5. Uriankhaiskii krai: ot Uriankhaia $k$ Tannu-Tuve (konets XIX - pervaia polovina XX v.) [Uriankhai Territory: from Uriankhai to Tannu-Tuva (late XIX - first half of XX century)]. 735 p. Pp. 618-729. (In Russ.).

Menkhen-Khel'fen, O. (2007) Puteshestvie v aziatskuiu Tuvu [A Journey to Asian Tuva]. In: Uriankhai. Tyva depter [Uriankhai: A Tuvan Notebook] : in 7 vols. / comp. by S. K. Shoigu. Moscow, Slovo/Slovo. Vol. 6. 584 p. Pp. 222-351. (In Russ.).

Mollerov, N. M. (2005) Istoriia sovetsko-tuvinskikh otnoshenii (1917-1944 gg.) [History of Soviet-Tuvan relations: 1917-1944]. Moscow, Moscow University for Humanities Publ. 326 p. (In Russ.).

Potapov, L. P. (1969) Ocherki narodnogo byta tuvintsev [The Tuvans: sketches of the folk lifestyle and related household activities]. Moscow, Nauka, GRVL. 402 p. (In Russ.).

Toka, S. K. (1987) Naveki vmeste [Forever together]. In: Slava Oktiabriu! [Glory to the October!], ed by A. K. Kanzai. Kyzyl, Tuvan book publisher. 219 p. Pp. 15-49. (In Russ.).

Shiriaeva, P. G. (1975) Iz istorii razvitiia nekotorykh revoliutsionnykh traditsii [From the history of the development of some revolutionary traditions]. Sovetskaia etnografia, no. 6, pp. 63-70. (In Russ.).

Tsyrenova, Z. E. (2007) Traditsionnaia kul'tura korennykh narodov Vostochnoi Sibiri (1920 - konets 1980-kh gg.): opyt sokhraneniia razvitiia [Traditional culture of the indigenous peoples of Eastern Siberia (1920 - late 1980s): conservation and development]: Abstract of Diss.... Doctor of History. Ulan-Ude. 51 p. (In Russ.).

Yusha, Zh. M. (2005) Traditsionnaia narodnaia obriadovaia poeziia tuvintsev: struktura i semantika [Traditional folk ritual poetry of Tuvans: structure and semantics]: Diss.... Candidate of Philology. Novosibirsk. 194 p. (In Russ.).

Yakovlev, E. K. (1900) Etnograficheskii obzor inorodcheskogo naseleniya doliny Yuzhnogo Eniseya i ob'yasnitel'nyi katalog Etnograficheskogo otdela Muzeya [An ethnographic review of the South Yenisei Valley and the explanatory catalogue of the Museum's Ethnography Research Department]. Minusinsk, V. I. Kornakov Publ. 357 p. (In Russ.).

Submission date: 15.06.2020. 